\title{
Cognitive function, depression, and anxiety in patients undergoing radical prostatectomy with and without adjuvant treatment
}

This article was published in the following Dove Medical Press journal: Neuropsychiatric Disease and Treatment

\author{
Piotr Jarzemski' \\ Bartosz Brzoszczyk' \\ Alicja Popiołek ${ }^{2}$ \\ Agnieszka \\ Stachowicz-Karpińska ${ }^{2}$ \\ Szymon Gołota ${ }^{2}$ \\ Maciej Bieliński² \\ Alina Borkowska ${ }^{2}$ \\ 'Department of Laparoscopic, \\ General, and Oncological Urology, \\ Jan Biziel University Hospital No 2, \\ Bydgoszcz, Poland; ${ }^{2}$ Department of \\ Clinical Neuropsychology, Nicolaus \\ Copernicus University in Toruń, \\ Collegium Medicum, Bydgoszcz, \\ Poland
}

Background: Prostate cancer (PC) is one of the most common malignant tumors in developed countries. Both PC and treatment for PC have an adverse impact on physical and mental wellbeing, and are associated with decreased quality of life. The aim of the present study was to examine the relationship between neuropsychological symptoms and clinical course in PC patients undergoing radical prostatectomy with or without adjunct therapy.

Methods: The cohort comprised 100 patients aged 50-77 years who underwent radical, laparoscopic prostatectomy for PC. Twenty-three patients with a more advanced clinical stage also received adjuvant therapy (radiotherapy and hormonotherapy). Clinical evaluation included self-report assessment, physical examination, and biochemical tests (testosterone and prostate-specific antigen). In addition, the presence and intensity of sexual dysfunction, urinary dysfunction, anxiety-depressive symptoms, and cognitive dysfunction were assessed.

Results: The group of patients undergoing complex therapy was characterized by a significantly worse result of deferred memory $(p=0.04)$. A significant correlation was found between postsurgery erectile function and scores for the visual working memory test (correct answers; VWMT-C; $p=0.006)$ and Hospital Anxiety and Depression Scale depression $(p=0.045)$ and anxiety scores $(p=0.02)$. A trend toward significance was also observed for simple reaction time (correct answers; $p=0.09$ ). A significant correlation was found between results for the delayed verbal memory test and all physical symptoms (International Consultation on Incontinence Questionnaire-total, $p=0.02$; International Index of Erectile Function-5, $p=0.006$ ). Similarly, a significant correlation was found between the VWMT-C and score for sexual dysfunction ( $p=0.003)$.

Conclusion: Patients undergoing both surgical and adjunct therapy for PC are at risk for psychological burden and cognitive disorders. In the present cohort, physical complications of therapy were associated with depression, anxiety, and delayed memory dysfunction. Furthermore, this study has proven that fewer complications after surgery are associated with better psychological and cognitive functioning. Appropriate neuropsychological and psychiatric care can improve compliance and quality of life among patients after prostatectomy.

Keywords: prostate cancer, cognition, anxiety, depression, sexual dysfunction

\section{Introduction}

Prostate cancer (PC) is one of the most common malignancies in developed countries. According to the American Cancer Society, among men in the US, PC is the most frequently diagnosed malignant tumor and the second leading cause of cancer death (after lung cancer). ${ }^{1}$ Both $\mathrm{PC}$ and treatment for $\mathrm{PC}$ have a negative impact on physical and mental well-being, and are associated with decreased quality of life..$^{2-7} \mathrm{PC}$ is often 
diagnosed after presentation with disease-related physical symptoms, and is frequently associated with anxiety concerning treatment and its possible consequences. ${ }^{8-10}$ Primary therapy for PC remains surgical radical prostatectomy. Over recent decades, numerous studies of $\mathrm{PC}$ have demonstrated a significant association between treatment method and the incidence of complications. ${ }^{11-13}$ All forms of surgical treatment are associated with periprocedural and deferred complications, which impact both the physical and psychological aspects of quality of life. ${ }^{2,13}$

The most commonly reported postoperative physical symptoms are sexual dysfunction and difficulties with micturition. ${ }^{11,14}$ The most common postoperative psychological symptoms are anxiety, ${ }^{15-17}$ chronic fatigue, ${ }^{18,19}$ and depression. ${ }^{15,16,20}$ Research has demonstrated an association between specific psychological symptoms and the prevalence and severity of sexual and urinary outcomes in the PC population. ${ }^{21}$

The most common forms of deterioration in sexual function in PC patients are erectile dysfunction (ED), ${ }^{22}$ difficulties in experiencing orgasm, ${ }^{23}$ shortening and/or deformation of the penis, ${ }^{24,25}$ fertility disorders, ${ }^{26}$ and reduced sex drive. ${ }^{20}$ These symptoms are associated with a reduced sense of masculinity and physical attractiveness. ${ }^{27-30}$ Research shows that PC patients with treatment-related ED often blame themselves for their postoperative sexual and relationship difficulties, and for their inability to meet the sexual needs of their partners. ${ }^{31}$ This is also the case for disorders of self-image and self-confidence, which may also interfere with personal relationships, in particular relationships with their partners. ${ }^{29,32}$

Research in PC patients has also demonstrated a significant deterioration in cognitive function. Several studies have demonstrated that cognitive dysfunction in this population is associated with hormonal disorders, including those arising as a result of hormonal therapy. ${ }^{33-35}$ In older adults from the nonPC population, better scores for cognitive functioning have been associated with sexual satisfaction and the frequency of sexual intercourse. ${ }^{36,37}$ To our knowledge, no study to date has investigated the relationship between sexual function and cognitive status in men undergoing radical prostatectomy for PC.

The aim of the present study was to examine the relationship between neuropsychological symptoms and clinical course in PC patients undergoing radical prostatectomy with or without adjunct therapy.

\section{Participants and methods Participants}

The cohort comprised 100 Caucasian patients with PC, who underwent laparoscopic radical prostatectomy and were recruited between July 1, 2017 and June 30, 2018 from the urological outpatient department of the Jan Biziel University Hospital No 2 in Bydgoszcz, Poland. The median age of the participants was 66 years (range: 50-77 years). Patients were evaluated once postoperatively, after an average of 27 months (minimum after 3 and a maximum of 102). A medical history was obtained and, if indicated, tests were performed to identify comorbid common diseases that have an impact on cognitive function (diabetes, hypertension, previous myocardial infarction, and stroke). Patients with either a psychiatric disorder or addiction to illicit drugs or alcohol were excluded, as categorized by the Diagnostic and Statistical Manual of Mental Disorders, 4th edition, as were those with any neurological abnormality. The study was approved by the Bioethical Commission of the Nicolaus Copernicus University, Collegium Medicum in Bydgoszcz (Approval No 476/2017). All participants provided written informed consent prior to inclusion. All study procedures were performed in accordance with the principles of the Declaration of Helsinki. A control group, including 112 men (aged 48-76 years and matched to age, $p=0.44$ ), with no significant somatic and mental diseases and in a stable clinical condition for at least 6 months, was selected as a reference for the results of Neurotest.

\section{Clinical PC staging and biochemical measures}

Prior to surgery, clinical PC stage was assessed via measurement of prostate-specific antigen (PSA) and magnetic resonance imaging of the prostate. At follow-up, besides complementary treatment, first ( 6 weeks post-surgery) and the actual PSA results were analyzed. In the adjunct therapy subgroup, biochemical failure was defined as a 6-week PSA level of $>0.2 \mathrm{ng} / \mathrm{mL}$. Free testosterone was measured at 6-week postoperative follow-up using an electrochemiluminescence immumoassay technique. All testosterone blood samples were drawn between 10:00 and 13:00 hours.

For the assessment of the local severity of PC (primary tumor staging), TNM classification and new contemporary PC grading system (GRADE Groups 1-5) were used. . $^{38,39}$

\section{International Index of Erectile Function (IIEF-5) questionnaire}

The IIEF-5 self-report questionnaire is a simplified version of the IIEF. Both questionnaires are characterized by high sensitivity and reliability in terms of the assessment of ED, irrespective of underlying etiology. The IIEF- 5 comprises five items. Four concern the prevalence and severity of ED, and one concerns satisfaction with sexual intercourse. Each item is scored on a 1-5 scale. Lower total scores indicate more severe ED. 


\section{Subjective assessment of erectile function}

Patients were asked to rate erectile function before and after surgery according to a scale of $1-5$ (1, no erection possible; 5 , no ED).

\section{International Consultation on Incontinence Questionnaire: Urinary Incontinence (IClQ-UI)}

The ICIQ-UI is a short self-report questionnaire that is used to assess the intensity of incontinence and its impact on quality of life in adults. The scale consists of four questions concerning the incidence of incontinence episodes, urine output during episodes of incontinence, and the degree to which incontinence interferes with daily functioning (frequency of urinary incontinence, amount of leakage, overall impact of urinary incontinence, self-diagnostic item). The respondent indicates the severity of the symptoms according to a multilevel scale. The test result is the sum of the scores obtained, where the minimum score is 0 and the maximum score is 21 . Higher scores indicate a greater impact on quality of life.

\section{Psychological assessment}

The presence and severity of anxiety and depressive symptoms were measured using the self-report Hospital Anxiety and Depression Scale (HADS). The HADS is comprised of two parts. These generate separate scores for anxiety (HADS-A) and depression (HADS-D). Each part comprises seven items. For each item, the respondent is asked to select one of the four answers, which are ranked in terms of symptom severity. For each part, the score is calculated as the sum of the responses to all seven items; the higher the score, the greater the severity of the reported anxiety or depression.

\section{Neurocognitive assessment}

Neurocognitive evaluation was performed using the "Neurotest" computer battery. This set of neuropsychological tests enables comprehensive assessment of cognitive function. The four individual tests are described in the following section.

\section{Simple reaction time (SRT)}

In the SRT task, the participant is asked to respond to a stimulus presented on the computer screen. The participant must press the computer key each time a green circle appears on the screen. The participant is instructed to react as fast as possible. The task is preceded by a trial version, in which the stimulus is presented five times. The number of correct responses and the average response time $(\mathrm{ms})$ are measured. The SRT task measures reaction time, general alertness, and motor speed.

\section{GoNoGo test}

The GoNoGo test involves two reactions, symbolically marked as "Go" and "NoGo". In the "Go" reaction, the participant is required to press the computer key when a green square appears on the computer screen. In the "NoGo" reaction, the participant is required not to react (not press the key) when a blue square appears on the screen. The stimuli (75 green and 25 blue squares) are presented in random order. The GoNoGo test assesses response times under the condition of the need to trigger cognitive control and cognitive inhibition. The number and percentage of incorrect and correct "Go" and "NoGo" reactions and the response time (ms) for correct "Go" reactions are examined. The primary purpose of the GoNoGo test is to assess inhibitory control.

\section{Verbal memory test (VMT) and delayed verbal memory test (VMDT)}

This test comprises five consecutive stages. The researcher reads a list of ten words five times to the participant. After each repetition, the participant is asked to recall the ten words in any order. The group of words read in each of the five repetitions is constant and unchangeable. For each repetition, the researcher records: the number of correctly repeated words, the number of intrusions (words from outside the list), and the number of perseverations (repetitions). After an interval of 20 minutes, the participant is asked to repeat the words from the original ten-item list, without having had them first read aloud by the researcher. The test evaluates immediate auditory memory (the number of words remembered), learning (improvement of results in subsequent repetitions), and deferred memory (remembering repeated words).

\section{Visual working memory test (VWMT)}

At the beginning of the test, seven covered playing cards are presented on the computer screen. The cards are then sequentially uncovered and recovered (each card is exposed for 2 seconds). The seven cards differ in terms of numbers and figures, as in a standard deck of playing cards. The participant is required to memorize the card layout. After presenting all seven cards, one of the previously presented cards is displayed at the top of the screen. The participant must indicate the previous location of the displayed card. In this way, all seven cards are displayed in sequence. The number of correctly and incorrectly indicated locations is recorded. This test assesses spatial memory.

\section{Statistical analysis}

Statistica 13.1 software was used for statistical analysis. In the first step, the Shapiro-Wilk test was used to assess the 
normality of the distribution of study variables. Since the distribution was non-normal, nonparametric tests were used in the subsequent analyses. The Mann-Whitney $U$-test was used to calculate the statistical significance of inter-group differences and Kruskall-Willis's ANOVA for differences between more than three groups. The R-Spearman test was used to determine the significance of the correlations. To facilitate inter-group comparisons, effect sizes were calculated using the Cohen's d method. A $p$-value of $<0.05$ was considered statistically significant.

\section{Results}

For the purposes of the present analyses, the cohort was divided into two treatment subgroups: 1) patients undergoing radical prostatectomy only $(\mathrm{n}=77)$ and 2$)$ patients undergoing radical prostatectomy and adjuvant treatment $(n=23)$. In this group, 15 patients underwent radiotherapy (radiotherapy was started 6 weeks after the surgery and the adjunct therapy was stopped 7 months after the procedure), two received only hormonal treatment (androgen-deprivation therapy [ADT]), and six patients underwent both forms of adjuvant treatment. The demographic and clinical data of the two study subgroups are shown in Table 1. No statistically significant inter-group differences were found in terms of demographic parameters, the presence of comorbidities, or physical activity. However, postoperative ED was more prevalent in the adjuvant therapy subgroup (percentage of patients with 1 point on IIEF-5 scale in the study subgroups $40 \%$ vs $61 \%$ ), while no significant differences were found in the score of IIEF results in the subgroups (Table 2). Similarly, no significant inter-group

Table I Demographic and clinical data of the two prostate cancer therapy subgroups

\begin{tabular}{|c|c|c|c|c|c|}
\hline Parameter & $\begin{array}{l}\text { Total } \\
(n=100)\end{array}$ & $\begin{array}{l}\text { Prostatectomy } \\
\text { only }(n=77)\end{array}$ & $\begin{array}{l}\text { Prostatectomy and } \\
\text { adjuvant treatment } \\
(n=23)\end{array}$ & Cohen's d & $p$-value \\
\hline Age (years) & $66.0(60.0-70.0)$ & $66.0(60.0-70.0)$ & $65.0(60.0-71.0)$ & 0.16 & 0.95 \\
\hline BMI $\left(\mathrm{kg} / \mathrm{m}^{2}\right)$ & $27.1(25.1-29.7)$ & $26.7(24.7-29.4)$ & $27.7(25.7-3 \mid .5)$ & 0.36 & 0.11 \\
\hline Diabetes (n, \%) & $13(13 \%)$ & II (14\%) & $2(8.5 \%)$ & & 0.69 \\
\hline Hypertension (n, \%) & $56(56 \%)$ & $42(54.5 \%)$ & $14(61 \%)$ & & 0.64 \\
\hline $\mathrm{MI}(\mathrm{n}, \%)$ & $9(9 \%)$ & $6(9.5 \%)$ & $3(13 \%)$ & & 0.71 \\
\hline Stroke $(\mathrm{n}, \%)$ & $7(7 \%)$ & $6(9.5 \%)$ & $\mathrm{I}(4 \%)$ & & 0.81 \\
\hline \multicolumn{4}{|l|}{ Education } & & \\
\hline Basic $(n, \%)$ & $5(5 \%)$ & $5(6.5 \%)$ & $0(0 \%)$ & & \multirow[t]{4}{*}{0.85} \\
\hline Vocational (n, \%) & $28(28 \%)$ & $19(24.5 \%)$ & $9(39 \%)$ & & \\
\hline Secondary (n, \%) & $34(34 \%)$ & 29 (37.5\%) & $5(22 \%)$ & & \\
\hline Higher (n, \%) & $33(33 \%)$ & $24(31.5 \%)$ & $9(39 \%)$ & & \\
\hline \multicolumn{4}{|l|}{ Physical activity } & & \\
\hline None (n, \%) & $34(34 \%)$ & $24(31 \%)$ & $10(43.5 \%)$ & & \multirow[t]{3}{*}{0.34} \\
\hline$<\mathrm{I} \times /$ week $(\mathrm{n}, \%)$ & $31(31 \%)$ & $20(26 \%)$ & II (48\%) & & \\
\hline$<3 \times /$ week & $35(35 \%)$ & $33(43 \%)$ & $2(8.5 \%)$ & & \\
\hline Nicotinism (n, \%) & $47(47 \%)$ & 37 (48\%) & $10(43.5 \%)$ & & 0.74 \\
\hline $\begin{array}{l}\text { Erectile dysfunction before } \\
\text { surgery }(0 / I)(n, \%)\end{array}$ & $6(6 \%)$ & $2(2.5 \%)$ & $4(14 \%)$ & & 0.96 \\
\hline $\begin{array}{l}\text { Erectile dysfunction after } \\
\text { surgery }(0 / 1)(n, \%)\end{array}$ & $20(20 \%)$ & $2(2.5 \%)$ & I8 (78\%) & & 0.022 \\
\hline Time from surgery (months) & $19.0(12.0-39.0)$ & $19.0(12.0-39.0)$ & $17.0(\mid 3.0-27.0)$ & 0.15 & 0.67 \\
\hline Grade group & $1.0(1.0-2.0)$ & $1.0(1.0-2.0)$ & $2.0(1.0-4.0)$ & 1.02 & 0.0002 \\
\hline \multicolumn{6}{|c|}{ TNM classification primary tumor staging } \\
\hline T2No (n, \%) & $\mathrm{I}(\mathrm{l} \%)$ & $\mathrm{I}(\mathrm{I} \%)$ & $0(0 \%)$ & & \multirow[t]{7}{*}{0.01} \\
\hline T2A (n, \%) & $13(13 \%)$ & $13(16.5 \%)$ & $0(0 \%)$ & & \\
\hline T2B (n, \%) & $\mathrm{I}(\mathrm{I} \%)$ & $0(0 \%)$ & I (4.5\%) & & \\
\hline $\mathrm{T} 2 \mathrm{C}(\mathrm{n}, \%)$ & $64(64 \%)$ & $61(79 \%)$ & $3(13 \%)$ & & \\
\hline T3A (n, \%) & $10(10 \%)$ & $0(0 \%)$ & $10(43.5 \%)$ & & \\
\hline T3B (n, \%) & $8(8 \%)$ & $\mathrm{I}(\mathrm{I} .5 \%)$ & $7(30 \%)$ & & \\
\hline T3C (n, \%) & $3(3 \%)$ & I (I.5\%) & $2(9 \%)$ & & \\
\hline
\end{tabular}

Notes: Data are shown as the median (25th-75th quartile) or number (\%). Inter-group differences were assessed using the Mann-Whitney U-test. Effect size was measured using the Cohen's $d$ method. Significant $p$-values are shown in bold.

Abbreviations: BMI, body mass index; MI, myocardial infarction; 0/I, presence or absence of erectile dysfunction. 
Table 2 Psychological, clinical, and biochemical parameters in prostate cancer therapy subgroups

\begin{tabular}{|c|c|c|c|c|c|}
\hline Parameter (ref value) & Total $(n=100)$ & $\begin{array}{l}\text { Prostatectomy only } \\
(n=77)\end{array}$ & $\begin{array}{l}\text { Prostatectomy and } \\
\text { adjuvant treatment } \\
(n=23)\end{array}$ & Cohen's d & $p$-value \\
\hline HADS-Anxiety & $3.0(1.0-7.0)$ & $3.0(1.0-6.0)$ & $5.0(3.0-9.0)$ & 0.70 & 0.01 \\
\hline HADS-Depression & $3.0(1.0-6.0)$ & $2.0(1.0-4.0)$ & $4.0(2.0-8.0)$ & 0.77 & 0.027 \\
\hline ICIQ-total & $3.0(0.0-8.0)$ & $2.0(0.0-7.0)$ & $7.0(0.0-13.0)$ & I.I & 0.045 \\
\hline IIEF-5 & $0.0(0.0-7.0)$ & $0.0(0.0-8.0)$ & $0.0(0.0-5.0)$ & 0.61 & 0.31 \\
\hline PSA-I (<4.I ng/mL) & $7.5(5.4-10.6)$ & $7.1(5.2-9.3)$ & $10.3(6.4-17.0)$ & 0.8 & 0.035 \\
\hline PSA-2 (<4.I ng/mL) & $0.003(0.003-0.037)$ & $0.003(0.003-0.017)$ & $0.008(0.003-0.14)$ & 0.09 & 0.045 \\
\hline Testosterone (1.23-8.92 ng/mL) & $4.63(3.15-6.26)$ & $5.2(3.49-6.4)$ & $3.56(2.47-4.5)$ & 0.70 & 0.001 \\
\hline
\end{tabular}

Notes: Data are shown as the median (25th-75th quartile). Inter-group differences were assessed using the Mann-Whitney $U$-test. Effect size was measured using the Cohen's $d$ method. Significant $p$-values are shown in bold.

Abbreviations: HADS, Hospital Anxiety and Depression Scale; ICIQ, International Consultation on Incontinence Modular Questionnaire; IIEF-5, International Index of Erectile Function; PSA, prostate-specific antigen; Ref value, reference values.

differences were found for the results of the neurocognitive test battery (Table 3). For the VMDT, the finding of better results in patients from the radical prostatectomy only subgroup showed a trend toward significance. The analysis of differences in cognitive test results between the test group and the control group showed a number of significant differences to the detriment of patients with $\mathrm{PC}$ in the areas of VMT, VWDT, GoNoGo, and VWMT, and no significant differences in the SRT results were found (Figures 1-4).

Adjuvant treatment showed a significant association with higher expressed depressive and anxiety symptoms and worse urinary outcomes. Significant inter-group differences in biochemical results were also observed, with a significantly lower testosterone level and significantly higher PSA-1 and PSA-2 levels being observed in the adjuvant therapy subgroup.

Tables 4 and 5 show the correlations between erectile function before and after surgery and demographic, clinical, biochemical, and neuropsychological data. Erection function after the surgery correlated significantly with the number of VWMT correct answers, and a trend toward statistical significance was observed for SRT correct answers and

Table 3 Cognitive test results for the prostate cancer therapy subgroups

\begin{tabular}{|l|l|l|l|l|l|}
\hline Parameter & $\begin{array}{l}\text { Total } \\
(\mathbf{n}=\mathbf{l 0 0})\end{array}$ & $\begin{array}{l}\text { Prostatectomy only } \\
(\mathbf{n}=\mathbf{7 7})\end{array}$ & $\begin{array}{l}\text { Prostatectomy and } \\
\text { adjuvant treatment } \\
(\mathbf{n}=\mathbf{2 3})\end{array}$ & Cohen's d & $\boldsymbol{p}$-value \\
\hline SRT-C & $25.0(25.0-25.0)$ & $25.0(25.0-25.0)$ & $25.0(25.0-25.0)$ & 0.005 & 0.92 \\
\hline SRT-RT (ms) & $280.8(234.3-319.1)$ & $281.3(234.6-316.9)$ & $274.7(233.3-343.9)$ & 0.29 & 0.73 \\
\hline VM-I & $5.0(4.0-7.0)$ & $5.0(5.0-6.0)$ & $5.0(4.0-7.0)$ & 1.52 & 0.60 \\
\hline VM-2 & $7.0(6.0-8.0)$ & $7.0(6.0-8.0)$ & $7.0(6.0-8.0)$ & 0.06 & 0.95 \\
\hline VM-3 & $7.0(7.0-8.0)$ & $7.0(7.0-8.0)$ & $8.0(6.0-8.0)$ & 0.07 & 0.83 \\
\hline VM-4 & $8.0(7.0-10.0)$ & $8.0(6.0-10.0)$ & $8.0(7.0-10.0)$ & 0.05 & 0.62 \\
\hline VM-5 & $8.0(7.0-10.0)$ & $8.0(6.0-10.0)$ & $8.0(7.0-10.0)$ & 0.05 & 0.64 \\
\hline VMDT & $6.0(5.0-7.0)$ & $6.0(5.0-7.0)$ & $5.0(4.0-7.0)$ & 0.64 & $\mathbf{0 . 0 4}$ \\
\hline GoNoGo-C & $74.0(73.0-75.0)$ & $74.0(73.0-75.0)$ & $74.0(73.0-75.0)$ & 0.10 & 0.90 \\
\hline GoNoGo-RT (ms) & $365.8(323.6-4 I 4.3)$ & $366.2(326.4-419.6)$ & $363.1(310.4-397.5)$ & 0.25 & 0.39 \\
\hline GoNoGo IncGO & $1.0(0.0-2.0)$ & $1.0(0.0-2.0)$ & $1.0(0.0-2.0)$ & 0.28 & 0.89 \\
\hline GoNoGo IncNoGo & $5.0(2.0-8.0)$ & $4.0(2.0-7.0)$ & $6.0(3.0-9.0)$ & 0.07 & 0.16 \\
\hline VWMT-C & $5.0(3.0-6.5)$ & $6.0(3.0-7.0)$ & $5.0(3.0-6.0)$ & 0.09 & 0.64 \\
\hline VWMT-CRT (ms) & $3,150.0(2,570.0-4,44 I .0)$ & $3,219.0(2,578.0-4,266.0)$ & $2,828.0(2,562.0-4,586.0)$ & 0.28 & 0.76 \\
\hline VWMT-IRT (ms) & $3,499.0(0.0-4,742.0)$ & $3,484.0(0.0-4,516.0)$ & $3,515.0(0.0-6,625.0)$ & 0.12 & 0.57 \\
\hline
\end{tabular}

Notes: Data are shown as the median (25th-75th quartile) or number (\%). Inter-group differences were assessed using the Mann-Whitney $U$-test. Effect size was measured using the Cohen's d method. Significant $p$-value is shown in bold.

Abbreviations: SRT-C, simple reaction time test (number of correct answers); SRT-RT, simple reaction time test (average reaction time); VM-I to VM-5, verbal memory (number of words remembered in each of the five attempts); VMDT, verbal delayed memory test (number of words remembered); GoNoGo-C, GoNoGo test (number of correct answers); RT, reaction time; IncGo, number of incorrect Go answers; IncNoGo, incorrect NoGo answers; VWMT-C, visual working memory test (number of correct answers); CRT, average response time for correct answers; IRT, average response time for incorrect answers. 


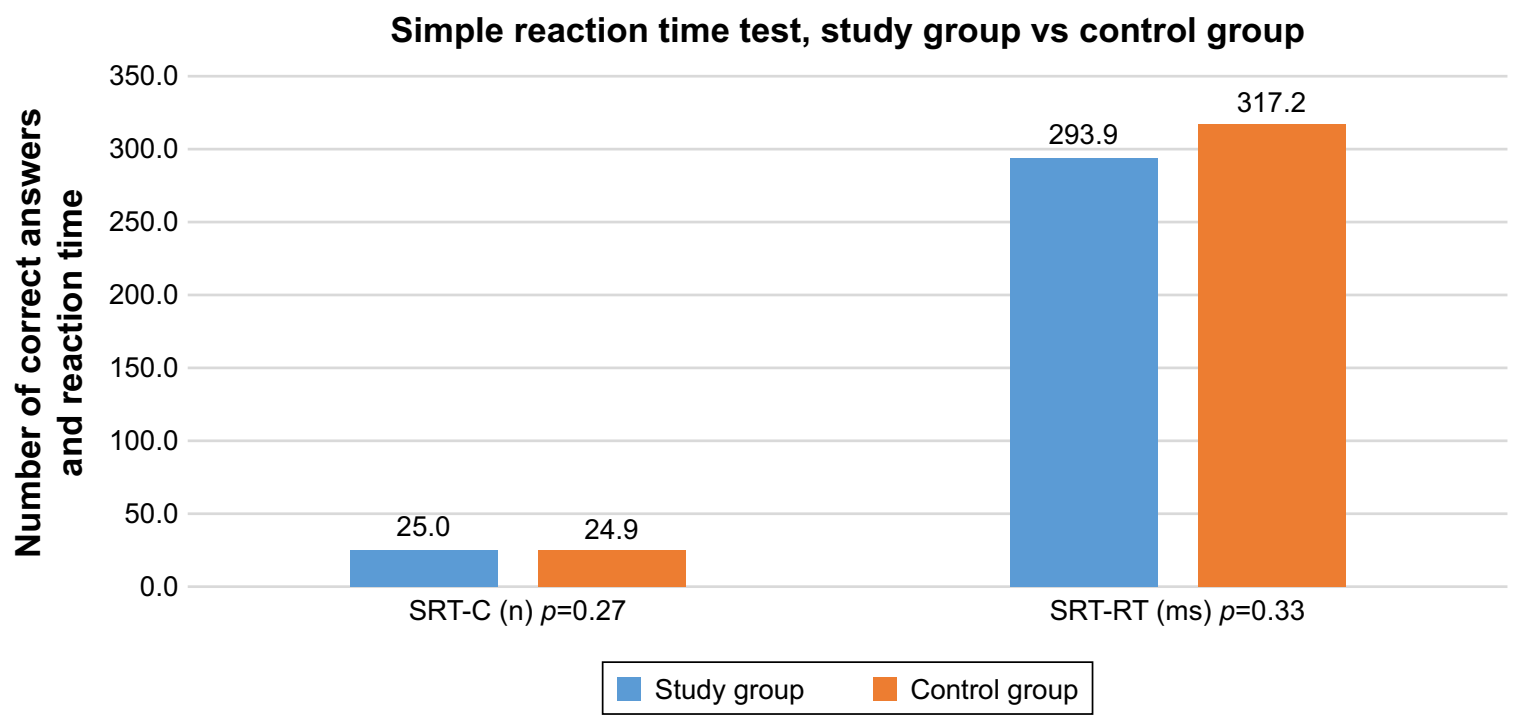

Figure I Simple reaction time test results in the study and control groups.

Abbreviations: SRT-C, simple reaction time test (number of correct answers); SRT-RT, simple reaction time test (average reaction time).

GoNoGo incorrect NoGo answers. A significant correlation was also found between GoNoGo reaction time and erectile function before surgery. Significant correlations were found between scores for HADS-A and HADS-D and erectile function after surgery.

The GRADE correlation analysis carried out with the results of cognitive tests and the analysis of differences in the results of patients with various grade group stages did not show any significant correlations.

The analysis of correlations between neurocognitive test results and biochemical results revealed a significant correlation between worse VMDT results and a higher level of PSA before surgery $(r=-0.303, p=0.018)$.
The neurocognitive test results were then correlated with the occurrence of the most common postoperative symptoms (Table 6). A significant correlation was found between results for the VMDT and both ICIQ-total and IIEF-5. Similarly, the number of correct responses in the VWMT showed a significant correlation with the results of the IIEF-5. No significant correlations were found for the remaining neurocognitive tests. The severity of depressive and anxiety symptoms showed a significant correlation with ICIQ.

\section{Discussion}

The present observational clinical study analyzed the demographic, clinical, biochemical, and neuropsychological

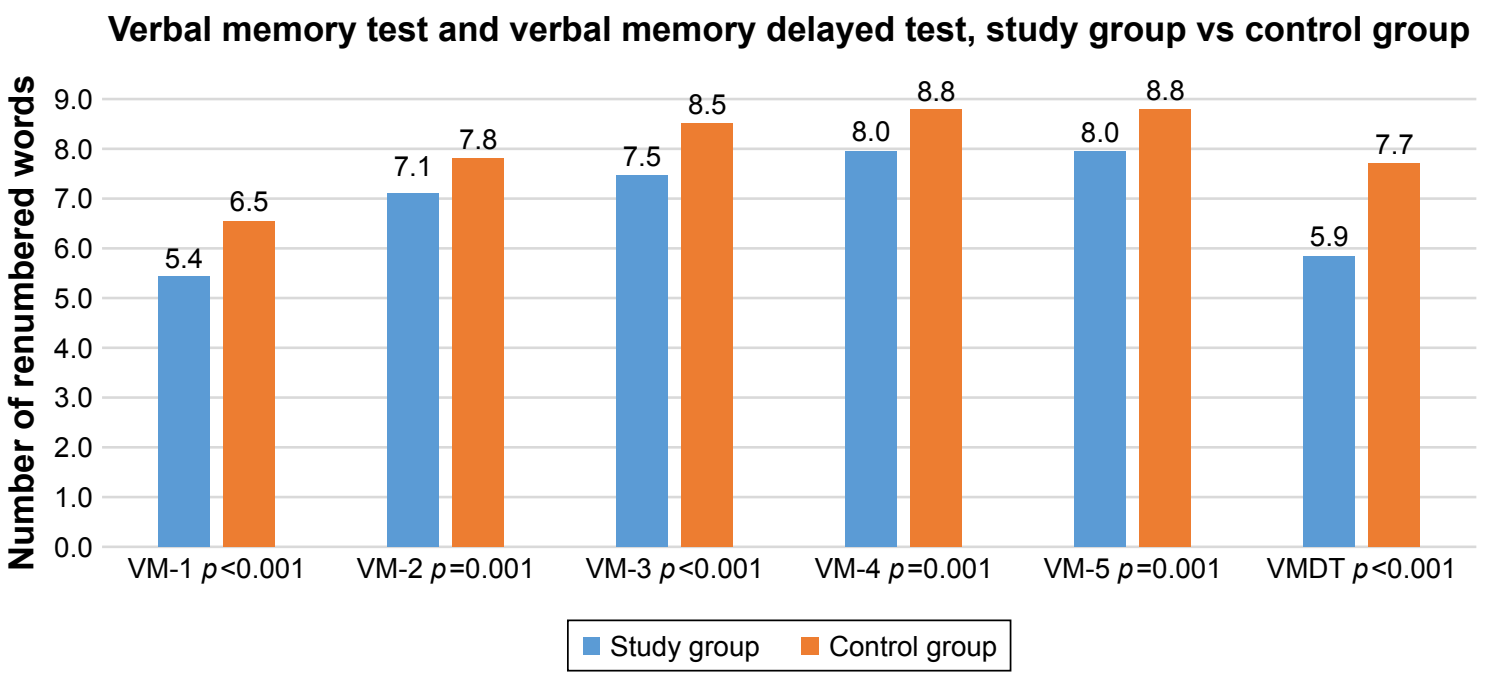

Figure 2 VMT and VMDT results in the study and control groups.

Abbreviations: VMT, verbal memory test; VM-I to VM-5, verbal memory (number of words remembered in each of the five attempts); VMDT, verbal delayed memory test (number of words remembered). 


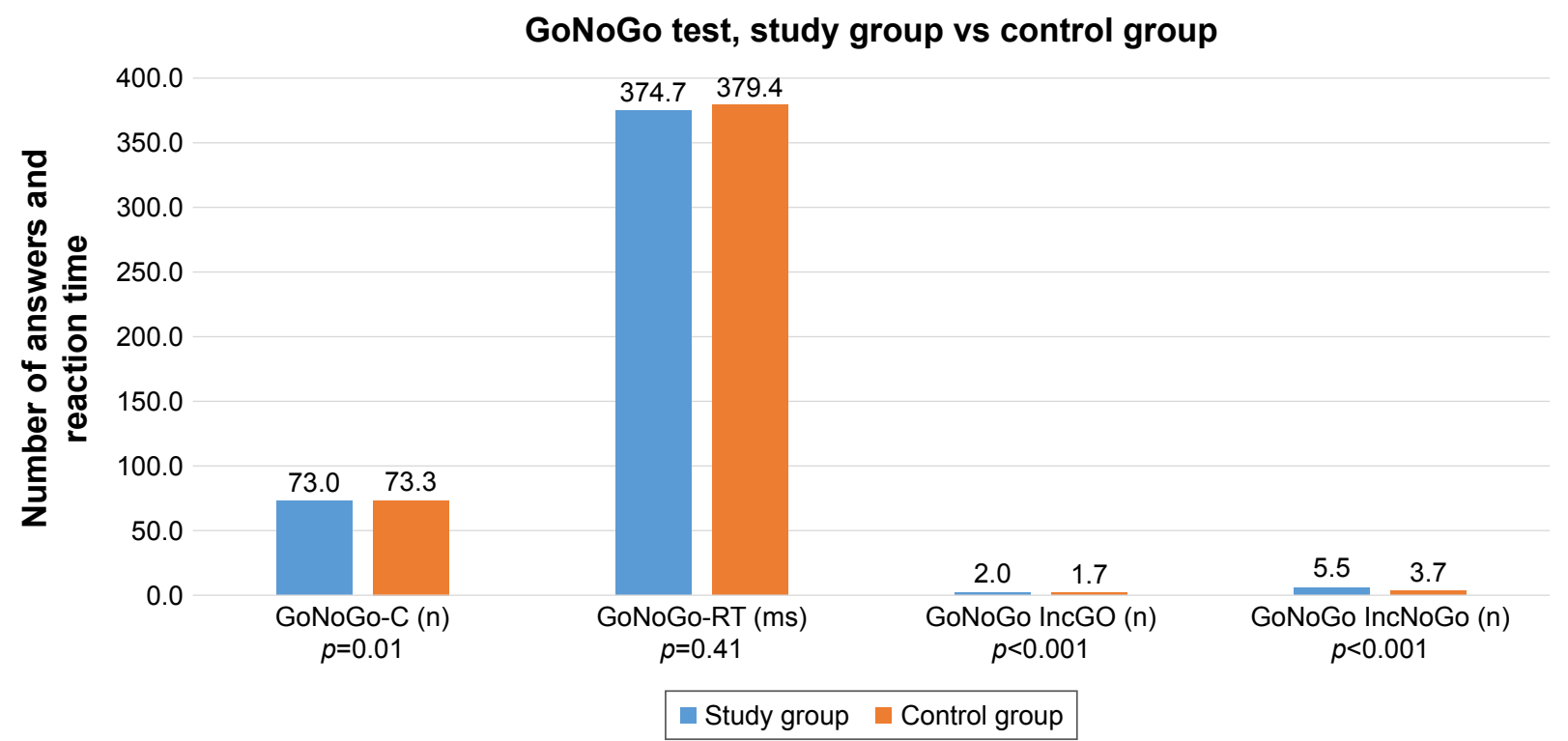

Figure 3 GoNoGo test results in the study and control groups.

Abbreviations: GoNoGo-C, GoNoGo test (number of correct answers); RT, reaction time; IncGo, number of incorrect Go answers; IncNoGo, incorrect NoGo answers.

characteristics of patients undergoing treatment for PC. The results indicate that personal and clinical factors determined psychological and cognitive outcomes. The main determinant of cognitive outcome in the present cohort was therapy type, ie, radical prostatectomy only versus radical prostatectomy with chemical and/or hormonal adjuvant therapy. The form and complexity of therapy was determined by the characteristics of the disease, whereby a more advanced clinical stage required the implementation of additional therapeutic methods.

Previous research shows that oncological therapy is associated with deterioration in cognitive functioning, particularly in the period immediately following treatment. ${ }^{40}$ A previous meta-analysis demonstrated visual and spatial cognitive dysfunction in patients undergoing hormonal treatment for PC, with no significant abnormalities being observed in other investigated cognitive domains. ${ }^{41}$ In the present cohort, intergroup differences were found for VMDT only (Table 3). No inter-group differences were found in terms of visual or spatial cognitive processes. However, similar results for deferred memory function have been reported in PC patients treated with radiotherapy, with no major deficits being detected in terms of attention or executive function.$^{42}$ Research in patients

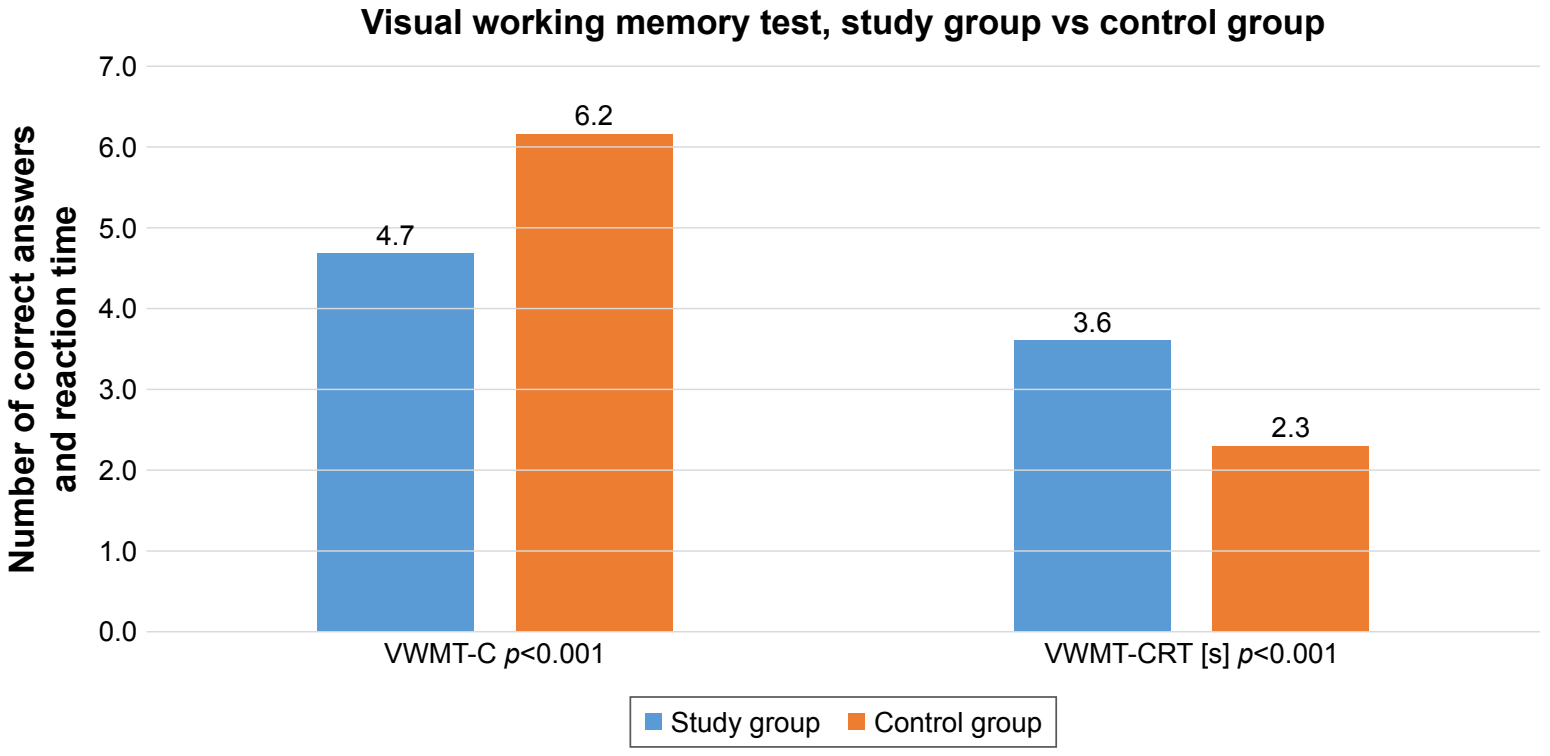

Figure 4 VWMT results in the study and control groups.

Abbreviations: WWMT-C, visual working memory test (number of correct answers); CRT, average response time for correct answers. 
Table 4 R-Spearman correlations between cognitive test results and erectile function before and after surgery in all groups $(n=100)$

\begin{tabular}{|l|l|l|l|l|}
\hline Parameter & $\begin{array}{l}\text { Erection } \\
\text { before } \\
\text { surgery }\end{array}$ & $\boldsymbol{p}$-value & $\begin{array}{l}\text { Erection } \\
\text { after } \\
\text { surgery }\end{array}$ & $p$-value \\
\hline SRT-C & -0.018 & 0.85 & -0.17 & $\mathbf{0 . 0 9}$ \\
\hline SRT-RT & -0.14 & 0.16 & -0.16 & 0.11 \\
\hline VM-I & 0.14 & 0.16 & -0.12 & 0.23 \\
\hline VM-2 & 0.18 & 0.07 & -0.15 & 0.13 \\
\hline VM-3 & 0.08 & 0.42 & -0.05 & 0.62 \\
\hline VM-4 & 0.09 & 0.37 & 0.02 & 0.84 \\
\hline VM-5 & 0.09 & 0.37 & 0.03 & 0.76 \\
\hline VMDT-C & 0.12 & 0.23 & 0.12 & 0.23 \\
\hline GoNoGo-C & -0.04 & 0.69 & 0.09 & 0.37 \\
\hline GoNoGo-RT & -0.21 & 0.03 & 0.03 & 0.76 \\
\hline $\begin{array}{l}\text { GoNoGo } \\
\text { IncGO }\end{array}$ & 0.04 & 0.69 & -0.09 & 0.37 \\
\hline $\begin{array}{l}\text { GoNoGo } \\
\text { IncNoGo }\end{array}$ & -0.05 & 0.62 & -0.17 & 0.09 \\
\hline VWMT-C & -0.03 & 0.76 & $\mathbf{0 . 2 7}$ & $\mathbf{0 . 0 0 6}$ \\
\hline VWMT-CRT & 0.05 & 0.62 & 0.03 & 0.76 \\
\hline VWMT-IRT & -0.05 & 0.62 & -0.13 & 0.13 \\
\hline Note: Sgnfan & & & & \\
\hline Var & & & & \\
\hline
\end{tabular}

Note: Significant $p$-values are shown in bold

Abbreviations: SRT-C, simple reaction time test (number of correct answers); SRT-RT, simple reaction time test (average reaction time); VM-I to VM-5, verbal memory (number of words remembered in each of the five attempts); VMDT-C, verbal delayed memory test correct answers (number of words remembered); GoNoGo-C, GoNoGo test (number of correct answers); RT, reaction time; IncGo, number of incorrect Go answers; IncNoGo, incorrect NoGo answers; VWMT-C, visual working memory test (number of correct answers); CRT, average response time for correct answers; IRT, average response time for incorrect answers.

Table 5 R-Spearman correlations between demographic, clinical, psychological, and biochemical factors and erectile function before and after surgery in all groups $(n=100)$

\begin{tabular}{|l|l|l|l|l|}
\hline Parameter & $\begin{array}{l}\text { Erection } \\
\text { before } \\
\text { surgery }\end{array}$ & $\mathbf{p}$-value & $\begin{array}{l}\text { Erection } \\
\text { after } \\
\text { surgery }\end{array}$ & $\mathbf{p}$-value \\
\hline Age (years) & $-\mathbf{0 . 2 2}$ & $\mathbf{0 . 0 2 7}$ & $-\mathbf{0 . 2 3}$ & $\mathbf{0 . 0 2}$ \\
\hline BMI (kg/m $)$ & -0.05 & 0.62 & $-\mathbf{0 . 2 9}$ & $\mathbf{0 . 0 0 3}$ \\
\hline $\begin{array}{l}\text { Time from } \\
\text { surgery (months) }\end{array}$ & - & - & $\mathbf{0 . 2 8}$ & $\mathbf{0 . 0 0 4}$ \\
\hline $\begin{array}{l}\text { PSA pre-surgery } \\
\text { (ng/mL) }\end{array}$ & 0.05 & 0.62 & -0.1 I & 0.27 \\
\hline $\begin{array}{l}\text { PSA post-surgery } \\
\text { (ng/mL) }\end{array}$ & -0.08 & 0.42 & $-\mathbf{0 . 2 1}$ & $\mathbf{0 . 0 3}$ \\
\hline $\begin{array}{l}\text { PSA actual } \\
\text { (ng/mL) }\end{array}$ & - & - & -0.05 & 0.62 \\
\hline $\begin{array}{l}\text { Testosterone } \\
\text { actual }(\mathrm{ng} / \mathrm{mL})\end{array}$ & - & - & $\mathbf{0 . 2 3}$ & $\mathbf{0 . 0 2}$ \\
\hline HADS-A & - & - & $-\mathbf{0 . 2 3}$ & $\mathbf{0 . 0 2}$ \\
\hline HADS-D & - & - & $-\mathbf{0 . 2 0}$ & $\mathbf{0 . 0 4 5}$ \\
\hline
\end{tabular}

Note: Significant $p$-values are shown in bold.

Abbreviations: HADS, Hospital Anxiety and Depression Scale; BMI, body mass index; PSA, prostate-specific antigen.
Table 6 R-Spearman correlations between clinical scales and cognitive test results

\begin{tabular}{|l|l|l|l|l|}
\hline Parameter & ICIQ-total & $\boldsymbol{p}$-value & IIEF-5 & $\boldsymbol{p}$-value \\
\hline VM-I & -0.14 & 0.16 & -0.04 & 0.69 \\
\hline VM-2 & -0.10 & 0.32 & -0.13 & 0.19 \\
\hline VM-3 & 0.02 & 0.84 & 0.07 & 0.48 \\
\hline VM-4 & -0.05 & 0.62 & 0.11 & 0.27 \\
\hline VM-5 & -0.04 & 0.69 & 0.12 & 0.23 \\
\hline VMDT-C & $-\mathbf{0 . 2 3}$ & $\mathbf{0 . 0 2}$ & $\mathbf{0 . 3 5}$ & $\mathbf{0 . 0 0 6}$ \\
\hline VWMT-C & -0.16 & 0.11 & $\mathbf{0 . 2 9}$ & $\mathbf{0 . 0 0 3}$ \\
\hline VWMT-CRT & 0.16 & 0.11 & 0.02 & 0.84 \\
\hline VWMT-IRT & 0.02 & 0.84 & 0.17 & 0.09 \\
\hline HADS-Anxiety & $\mathbf{0 . 2 3}$ & $\mathbf{0 . 0 2}$ & $-\mathbf{0 . 2 2}$ & $\mathbf{0 . 0 2}$ \\
\hline HADS-Depression & $\mathbf{0 . 3 8}$ & $\mathbf{0 . 0 0 0 0 9}$ & -0.13 & 0.19 \\
\hline
\end{tabular}

Note: Significant $p$-values are shown in bold.

Abbreviations: HADS, Hospital Anxiety and Depression Scale; ICIQ, International Consultation on Incontinence Modular Questionnaire; IIEF-5, International Index of Erectile Function; VM-I to VM-5, verbal memory correct answers (number of words remembered in each of the five attempts); VMDT-C, verbal delayed memory test correct answer (number of words remembered); VWMT-C, visual working memory test (number of correct answers); CRT, average response time for correct answers; $I R T$, average response time for incorrect answers.

with atrial fibrillation shows that delayed memory dysfunction is associated with a more advanced disease state. ${ }^{43}$

Further analyses showed that patients in the (more aggressive) adjunct therapy subgroup displayed more severe anxiety and depressive symptoms (Table 2). These symptoms are recognized risk factors for cognitive decline. ${ }^{44}$ However, no significant association was found in the present cohort between the severity of anxiety and depression and scores in the neurocognitive test battery. Research suggests that the occurrence of psychological disorders, in particular anxiety and depression, secondary to oncological treatment for PC is associated with poorer global functioning, and thus requires appropriate treatment. ${ }^{17,45}$

Subsequent analyses in the present cohort concerned the relationship between neuropsychological parameters and biochemical parameters of PC. Analysis of individual determinants of disease severity confirmed significant correlations between worse VMDT results and a higher level of PSA before surgery ( $r=-0.303, p=0.018)$. The latter is associated with a more advanced disease state. By contrast, lower testosterone levels showed no association with worse cognitive performance, more severe symptoms of anxiety and depression, or subjective assessment of erection quality (Table 5). Previous data on the relationship between cognitive status and testosterone levels in older men undergoing treatment for PC are equivocal. Salminem et al found correlations 
between low testosterone levels and deterioration in psychomotor speed, slowed reaction time in some attention tests, and impairments in delayed recall and letter recognition speed. ${ }^{46}$ Research suggests that the primary determinant of cognitive dysfunction in the context of PC treatment and reduced testosterone levels is ADT. ${ }^{47,48}$ However, some studies have found no effect of ADT on cognitive functioning. ${ }^{49}$ Other reports suggest that the emergence of cognitive dysfunction following ADT therapy for PC is attributable to other factors, for example, genetic susceptibility. ${ }^{50}$ In neuroimaging studies, ADT has been found to reduce the amount of gray matter in the anterior cortex, dorsolateral prefrontal cortex, and primary motor cortex. ${ }^{51}$ However, a meta-analysis conducted in 2016 concluded that no clear evidence is yet available concerning either the mechanism or the nature of postoperative cognitive dysfunction in patients undergoing hormonal treatment for PC. ${ }^{52}$

Another important aspect of the present study was the analysis of the physical consequences of treatment. For this purpose, two issues were examined: 1) the impact of urinary incontinence on quality of life and 2) subjective and objective evaluation of erection quality. These complications are associated with a high psychological burden and a reduction in quality of life. Analysis of erection quality, as assessed subjectively on a scale of $1-5$, revealed no inter-group differences. Available studies suggest that ED occurs in up to $89 \%$ of patients following treatment for PC. ${ }^{53}$ These results correspond to those obtained in the present adjunct therapy subgroup. These patients were also characterized by a significantly higher PSA level before and after surgery and a significantly lower postoperative testosterone level compared with patients undergoing surgical treatment only (Table 2).

Analysis of correlations between the cognitive tests, the HADS, and the ICIQ-total indicated a significant correlation between the results for delayed memory and ICIQ scores (Table 6). A significant association was found between worse ICIQ parameters and more severe anxiety and depressive symptoms. Urinary continence is an important aspect of quality of life in this population. Research has shown that around $40 \%$ of patients rate their quality of life as significantly decreased following treatment for $\mathrm{PC}$, and that this is impacted by therapy type. However, a study of patients from Nordic countries suggests that the highest percentage of dissatisfaction with quality of life is found among untreated PC patients. ${ }^{54}$

The present results indicate the value of both deferred memory parameters in combination with disease stage and the relevance of psychological symptoms, for predicting clinical course following treatment for PC.

\section{Limitations}

The results and conclusions of this study are mainly limited by a small group of respondents. In addition, single assessment of patients at different times after surgery makes drawing unambiguous conclusions difficult.

\section{Conclusion}

Patients undergoing both surgical and adjunct therapy for PC are at risk of cognitive dysfunction and symptoms of anxiety and depression. The present data suggest that the clinical course of postoperative psychological disorder is determined by clinical disease stage and treatment method. Physical complications of treatment are associated with a decrease in quality of life and delayed memory dysfunction. Furthermore, this study has proven that fewer complications after surgery are associated with better psychological and cognitive functioning. Appropriate neuropsychological and psychiatric care can improve compliance and quality of life among patients after prostatectomy. In addition, adequate care and treatment for ED and urinary incontinence may translate into clinical improvement.

\section{Acknowledgments}

The authors received no external funding for the conduct of the present research.

\section{Disclosure}

The authors report no conflicts of interest in this work.

\section{References}

1. Siegel RL, Miller KD, Jemal A. Cancer statistics, 2018. CA Cancer J Clin. 2018;68(1):7-30. doi:10.3322/caac.21442

2. Lehto US, Tenhola H, Taari K, Aromaa A. Patients' perceptions of the negative effects following different prostate cancer treatments and the impact on psychological well-being: a nationwide survey. Br J Cancer. 2017;116(7):864-873. doi:10.1038/bjc.2017.30

3. Maguire R, Hanly P, Drummond FJ, Gavin A, Sharp L. Expecting the worst? The relationship between retrospective and prospective appraisals of illness on quality of life in prostate cancer survivors. Psychooncology. 2018;27(4):1237-1243

4. Taylor KL, Luta G, Hoffman RM, et al. Quality of life among men with low-risk prostate cancer during the first year following diagnosis: the PREPARE prospective cohort study. Transl Behav Med. 2018;8: 156-165. doi:10.1093/tbm/ibx005

5. Sanda MG1, Dunn RL, Michalski J, et al. Quality of life and satisfaction with outcome among prostate-cancer survivors. N Engl J Med. 2008; 358(12):1250-1261. doi:10.1056/NEJMoa074311

6. Clark JA, Inui TS, Silliman RA, et al. Patients' perceptions of quality of life after treatment for early prostate cancer. J Clin Oncol. 2003; 21(20):3777-3784. doi:10.1200/JCO.2003.02.115 
7. Jang JW, Drumm MR, Efstathiou JA, et al. Long-term quality of life after definitive treatment for prostate cancer: patient-reported outcomes in the second posttreatment decade. Cancer Med. 2017;6(7):1827-1836. doi:10.1002/cam4.1103

8. Prostate Cancer Treatment (PDQ ${ }^{\circledR}$ ). Health professional version. PDQ cancer information summaries [Internet]. PDQ Adult Treatment Editorial Board. Available from: https://www.ncbi.nlm.nih.gov/books/ NBK66036. Accessed February 6, 2018.

9. Kong EH, Deatrick JA, Bradway CK. Men's experiences after prostatectomy: a meta-synthesis. Int J Nurs Stud. 2017;74:162-171. doi:10. 1016/j.ijnurstu.2017.07.013

10. Sharpley CF, Christie DRH, Bitsika V, et al. Neurobiological and psychological evidence of chronic stress in prostate cancer patients. Eur J Cancer Care (Engl). 2017;26:6. doi:10.1111/ecc.12671

11. Perez MA, Meyerowitz BE, Lieskovsky G, Skinner DG, Reynolds B, Skinner EC. Quality of life and sexuality following radical prostatectomy in patients with prostate cancer who use or do not use erectile aids. Urology. 1997;50(5):740-746. doi:10.1016/S0090-4295(97) 00327-0

12. Koike H, Kohjimoto Y, Iba A, et al. Health-related quality of life after robot-assisted radical prostatectomy compared with laparoscopic radical prostatectomy. J Robot Surg. 2017;11(3):325-331. doi:10.1007/ s11701-016-0659-8

13. Gershman B, Psutka SP, McGovern FJ, et al. Patient-reported functional outcomes following open, laparoscopic, and robotic assisted radical prostatectomy performed by high-volume surgeons at high-volume hospitals. Eur Urol Focus. 2016;2(2):172-179. doi:10.1016/j.euf. 2015.06.011

14. Trofimenko V, Myers JB, Brant WO. Post-prostatectomy incontinence: how common and bothersome is it really? Sex Med Rev. 2017;5(4): 536-543. doi:10.1016/j.sxmr.2017.05.001

15. Couper JW, Love AW, Dunai JV, et al. The psychological aftermath of prostate cancer treatment choices: a comparison of depression, anxiety and quality of life outcomes over the 12 months following diagnosis. Med J Aust. 2009;190(7 Suppl):S86-S89.

16. Pastore AL, Mir A, Maruccia S, et al. Psychological distress in patients undergoing surgery for urological cancer: a single centre cross-sectional study. Urol Oncol. 2017;35(12):673.e1-673.e7. doi:10.1016/j.urolonc. 2017.08.006

17. Meissner VH, Herkommer K, Marten-Mittag B, Gschwend JE, Dinkel A. Prostate cancer-related anxiety in long-term survivors after radical prostatectomy. J Cancer Surviv. 2017;11(6):800-807. doi:10.1007/ s11764-017-0619-y

18. McConkey RW. The psychosocial dimensions of fatigue in men treated for prostate cancer. Int J Urol Nurs. 2016;10(1):37-43. doi:10.1111/ ijun. 12089

19. Köhler N, Gansera L, Holze S, et al. Cancer-related fatigue in patients before and after radical prostatectomy. Results of a prospective multi centre study. Support Care Cancer. 2014;22(11):2883-2889. doi:10.1007/ s00520-014-2265-5

20. Boeri L, Capogrosso P, Ventimiglia E, et al. Depressive symptoms and low sexual desire after radical prostatectomy: early and long-term outcomes in a real-life setting. J Urol. 2018;199(2):474-480. doi:10.1016/j. juro.2017.08.104

21. Punnen S, Cowan JE, Dunn LB, Shumay DM, Carroll PR, Cooperberg MR. A longitudinal study of anxiety, depression and distress as predictors of sexual and urinary quality of life in men with prostate cancer. BJU Int. 2013;112(2):E67-E75. doi:10.1111/bju.12209

22. Fode M, Serefoglu EC, Albersen M, Sønksen J. Sexuality following radical prostatectomy: is restoration of erectile function enough? Sex Med Rev. 2017;5(1):110-119. doi:10.1016/j.sxmr.2016.07.005

23. Clavell-Hernández J, Martin C, Wang R. Orgasmic dysfunction following radical prostatectomy: review of current literature. Sex Med Rev. 2018;6(1):124-134. doi:10.1016/j.sxmr.2017.09.003

24. Kadono Y, Machioka K, Nakashima K, et al. Changes in penile length after radical prostatectomy: investigation of the underlying anatomical mechanism. BJU Int. 2017;120(2):293-299. doi:10.1111/bju.13777
25. Frey AU, Sønksen J, Fode M. Neglected side effects after radical prostatectomy: a systematic review. $J$ Sex Med. 2014;11(2):374-385. doi:10.1111/jsm. 12403

26. Tran S, Boissier R, Perrin J, Karsenty G, Lechevallier E. Review of the different treatments and management for prostate cancer and fertility. Urology. 2015;86(5):936-941. doi:10.1016/j.urology.2015.07.010

27. Chambers SK, Chung E, Wittert G, Hyde MK. Erectile dysfunction, masculinity, and psychosocial outcomes: a review of the experiences of men after prostate cancer treatment. Transl Androl Urol. 2017;6(1): 60-68. doi:10.21037/tau.2016.08.12

28. Zaider T, Manne S, Nelson C, Mulhall J, Kissane D. Loss of masculine identity, marital affection, and sexual bother in men with localized prostate cancer. J Sex Med. 2012;9(10):2724-2732. doi:10. 1111/j.1743-6109.2012.02897.x

29. Bokhour BG, Clark JA, Inui TS, Silliman RA, Talcott JA. Sexuality after treatment for early prostate cancer: exploring the meanings of "erectile dysfunction". J Gen Intern Med. 2001;16(10):649-655.

30. Gannon K, Guerro-Blanco M, Patel A, Abel P. Re-constructing masculinity following radical prostatectomy for prostate cancer. Aging Male. 2010;13(4):258-264. doi:10.3109/13685538.2010.487554

31. Meyer JP, Gillatt DA, Lockyer R, Macdonagh R. The effect of erectile dysfunction on the quality of life of men after radical prostatectomy. BJU Int. 2003;92(9):929-931.

32. Wennick A, Jönsson AK, Bratt O, Stenzelius K. Everyday life after a radical prostatectomy - a qualitative study of men under 65 years of age. Eur J Oncol Nurs. 2017;30:107-112. doi:10.1016/j.ejon. 2017.08.008

33. Morote J, Tabernero ÁJ, Álvarez-Ossorio JL, et al; Grupo de investigación ANAMEM. Cognitive function in patients on androgen suppression: A prospective, multicentric study. Actas Urol Esp. 2018; 42(2):114-120. doi: 10.1016/j.acuro.2017.04.007.

34. Mundell NL, Daly RM, Macpherson H, Fraser SF. Cognitive decline in prostate cancer patients undergoing ADT: a potential role for exercise training. Endocr Relat Cancer. 2017;24(4):R145-R155. doi:10.1530/ ERC-16-0493

35. Gunlusoy B, Ceylan Y, Koskderelioglu A, et al. Cognitive effects of androgen deprivation therapy in men with advanced prostate cancer. Urology. 2017;103:167-172. doi:10.1016/j.urology.2016.12.060

36. Wright H, Jenks RA, Demeyere N. Frequent Sexual Activity Predicts Specific Cognitive Abilities in Older Adults. J Gerontol B Psychol Sci Soc Sci. 2019;74(1):47-51. doi: 10.1093/geronb/gbx065.

37. Wright H, Jenks RA. Sex on the brain! Associations between sexual activity and cognitive function in older age. Age Ageing. 2016;45(2): 313-317. doi:10.1093/ageing/afv197

38. Cheng L, Montironi R, Bostwick DG, Lopez-Beltran A, Berney DM. Staging of prostate cancer. Histopathology. 2012;60(1):87-117. doi:10. 1111/j.1365-2559.2011.04025.x

39. Epstein JI. A new contemporary prostate cancer grading system. Ann Pathol. 2015;35(6):474-476. doi:10.1016/j.annpat.2015.09.00

40. Zuniga KE, Bishop NJ. Recent cancer treatment and memory decline in older adults: an analysis of the 2002-2012 Health and Retirement Study. J Geriatr Oncol. 2018;9(3):186-193.

41. McGinty HL, Phillips KM, Jim HS, et al. Cognitive functioning in men receiving androgen deprivation therapy for prostate cancer: a systematic review and meta-analysis. Support Care Cancer. 2014;22(8): 2271-2280. doi:10.1007/s00520-014-2285-1

42. Feng LR, Espina A, Saligan LN. Association of fatigue intensification with cognitive impairment during radiation therapy for prostate cancer. Oncology. 2018;94:363-372. doi:10.1159/000487081

43. Mietła B, Budzyński J, Bieliński M, Mieczkowski A, Pulkowska-Ulfig J, Borkowska A. Links between parameters of long-term latent memory and progression from paroxysmal to permanent atrial fibrillation during a five-year observation period. A preliminary study. Kardiol Pol. 2016; 74(8):754-776.

44. de Vito A, Calamia M, Greening S, Roye S. The association of anxiety, depression, and worry symptoms on cognitive performance in older adults. Neuropsychol Dev Cogn B Aging Neuropsychol Cogn. 2017;20:1-13. 
45. Watts S, Leydon G, Birch B, et al. Depression and anxiety in prostate cancer: a systematic review and meta-analysis of prevalence rates. BMJ Open. 2014;4(3):e003901. doi:10.1136/bmjopen-2013-003901

46. Salminen EK, Portin RI, Koskinen A, Helenius H, Nurmi M. Associations between serum testosterone fall and cognitive function in prostate cancer patients. Clin Cancer Res. 2004;10(22):7575-7582. doi:10. 1158/1078-0432.CCR-04-0750

47. Wu LM, Tanenbaum ML, Dijkers MP, et al. Cognitive and neurobehavioral symptoms in patients with non-metastatic prostate cancer treated with androgen deprivation therapy or observation: a mixed methods study. Soc Sci Med. 2016;156:80-89. doi:10.1016/j.socscimed.2016.03.016

48. Nelson CJ, Lee JS, Gamboa MC, Roth AJ. Cognitive effects of hormone therapy in men with prostate cancer: a review. Cancer. 2008;113(5): 1097-1106. doi:10.1002/cncr.23658

49. Chao HH, Uchio E, Zhang S, et al. Effects of androgen deprivation on brain function in prostate cancer patients - a prospective observational cohort analysis. BMC Cancer. 2012;12:37. doi:10.1186/14712407-12-371
50. Gonzalez BD, Jim HS, Booth-Jones M, et al. Course and predictors of cognitive function in patients with prostate cancer receiving androgendeprivation therapy: a controlled comparison. J Clin Oncol. 2015;33(18): 2021-2027. doi:10.1200/JCO.2014.60.1963

51. Chao HH, Hu S, Ide JS, et al. Effects of androgen deprivation on cerebral morphometry in prostate cancer patients - an exploratory study. PLoS One. 2013;8(8):e72032. doi:10.1371/journal.pone.0072032

52. Hua JT, Hildreth KL, Pelak VS. Effects of testosterone therapy on cognitive function in aging: a systematic review. Cogn Behav Neurol. 2016;29(3):122-138. doi:10.1097/WNN.0000000000000104

53. Chappidi MR, Kates M, Sopko NA, et al. Erectile dysfunction treatment following radical cystoprostatectomy: analysis of a nationwide insurance claims database. J Sex Med. 2017;14(6):810-817. doi:10.1016/j. jsxm.2017.04.002

54. Fosså SD, Bengtsson T, Borre M, Ahlgren G, Rannikko A, Dahl AA. Reduction of quality of life in prostate cancer patients: experience among 6200 men in the Nordic countries. Scand J Urol. 2016;50(5):330-337. doi: $10.1080 / 21681805.2016 .1201859$
Neuropsychiatric Disease and Treatment

\section{Publish your work in this journal}

Neuropsychiatric Disease and Treatment is an international, peerreviewed journal of clinical therapeutics and pharmacology focusing on concise rapid reporting of clinical or pre-clinical studies on a range of neuropsychiatric and neurological disorders. This journal is indexed on PubMed Central, the 'PsycINFO' database and CAS,

\section{Dovepress}

and is the official journal of The International Neuropsychiatric Association (INA). The manuscript management system is completely online and includes a very quick and fair peer-review system, which is all easy to use. Visit http://www.dovepress.com/testimonials.php to read real quotes from published authors.

Submit your manuscript here: http://www.dovepress.com/neuropsychiatric-disease-and-treatment-journal 